\title{
Khat chewing and its associated factor among College students in Bahir Dar town, Ethiopia
}

\author{
Yeshalem Mulugeta
}

Department of Public Health, Medical and Health Science College, Bahir Dar University, P.O.Box.79, Bahir Dar University, Ethiopia

\section{Email address:}

Yeshalem_mulugeta@yahoo.com

\section{To cite this article:}

Yeshalem Mulugeta. Khat Chewing and Its Associated Factor among College Students in Bahir Dar Town, Ethiopia. Science Journal of Public Health. Vol. 1, No. 5, 2013, pp. 209-214. doi: 10.11648/j.sjph.20130105.14

\begin{abstract}
Background: - Khat is a large green shrub that grows at high altitude in the region extending from eastern to southern Africa, as well as on the Arabian Peninsula. Khat is widely consumed among the youth of Ethiopia; especially among high school, College and University students. Khat chewing is the risk of frequently absenteeism from class and poor academic performance of the students. Moreover, it has serious health, social and economic consequence. However, information on prevalence and its associated factor is scarce in the study area. This study was conducted with the objective of assessing the prevalence of khat chewing and its associated factor among College students in Bahir Dar town, Ethiopia. Methods: - School based cross-sectional survey was conducted in May 2012 among 754 College students in Bahir Dar town, Ethiopia. Data were collected using pre-tested structured facilitator guided self administered questionnaire. Multi stage sampling technique was used to select students for the survey. The collected data were cleaned, coded and entered on to EPi-Info version 3.5.2 Statistical package soft ware. Data were exported to SPSS version 16 program for analysis. The proportion of youth reported khat chewing was computed. Logistic regression model was used to identify factors associated with khat chewing. Result- the overall prevalence of khat chewing in College students was 146 (19.6\%). The factors associated with khat chewing were being male [Adjusted $\mathrm{OR}=5.88,95 \% \mathrm{CI}=(3.18,10.87)$ ], having pocket money [Adjusted $\mathrm{OR}=3.42,95 \% \mathrm{CI}=(2.04,5.76)]$, urban residence $[$ Adjusted $\mathrm{OR}=4.09,95 \% \mathrm{CI}=(2.38,7.01)$ ], peer pressure [Adjusted $\mathrm{OR}=13.16,95 \% \mathrm{CI}=(6.89,25.17)]$, and parental model [Adjusted $\mathrm{OR}=4.28,95 \% \mathrm{CI}=(1.96,9.35)]$. Conclusion -The prevalence of khat chewing was high among College students in the study area. Factors that significantly affect the habit of khat chewing were identified. Colleges and health Bureau should design and implement audience specific behavioral change communication about consequence of khat chewing to prevent and avert students khat chewing practice.
\end{abstract}

Keywords: Khat, Youth, College Students, Ethiopia

\section{Introduction}

Khat (Catha edulis) is a large green shrub that grows at high altitude in the region extending from eastern to Southern Africa, as well as on the Arabian Peninsula; mainly in Ethiopia, Somalia, Kenya, Malawi, Uganda, Tanzania, Congo, Zambia, Zimbabwe, Afghanistan, Yemen and Madagascar $(1,2)$. Khat leaves mainly contain naturally occurring alkaloid amphetamines (cathinone and cathine) (3). These alkaloid amphetamines are responsible for its stimulant action. The leaves of khat are chewed by the people for its pleasurable stimulant action $(3,4)$.

In Ethiopia, khat chewing has deep rooted history as early as fourteenth century (2).Khat is commonly used for social and religious purposes (5). Furthermore, it considered as a recreational substance (6). Recently, khat chewing becomes a common practice among high school, College and University students. Students have consumed khat to be alert and wakeful at night; especially during examination periods. Moreover, they used it as a recreational substance. Among undergraduate medical students of Addis Ababa University; $14 \%$ of the participants chewed khat (7). In Dire Dawa high school $18.4 \%$ of students chewed khat (8).In a similar manner other sections of the community; such as, laborers, truck drivers, craftsmen, teachers and farmers have chewed khat in order to reduce fatigue, increase performance and to suppress appetite. In Jimma town 37.8\% of the communities reported khat chewing practice (9).

Khat chewing has major effect on the gastro-intestinal system, central nervous system, cardiovascular system and urinary system. Central nervous system effects of khat chewing are alertness, dependence, tolerance, anxiety, 
depression, manic, delusion and insomnia (4, 9-11). Gastro-intestinal system effects of khat chewing are dental problem, stomach ulcer, constipation, oral and esophageal cancer $(3,12)$. On cardiovascular system habitual use of khat causes hypertension, arrhythmia, myocardial infarction, stroke and death $(13,14)$. On urinary system habitual use of khat causes urinary retention(4).

Khat has implication on economical of the country and at house hold level; replacement of coffee and other crops for khat would be detrimental to the economy by draining foreign investment(5). At the house hold level, khat divert household income that could have been used for nutritious food, home improvement, education or other family needs to purchase khat that causes financial problem and family breakdown $(11,12)$.

Socially, Khat chewers spent long hours to chewing and then recovering from chewing; this causes absenteeism from work, a barrier to obtaining employment and lack of integration of khat-consuming communities(6, 13). Furthermore, it has implication on use of drugs and/or alcohol, smoking cigarette and sexual risk behaviors(14). Khat chewing is the risk of frequently absenteeism from class and poor academic performance of the students(15, 16).

Khat chewers had significantly higher mortality rate due to chronic illness; such as, heart disease and stroke compared with non-khat chewers. Khat chewers with chronic illness need more drug management than non chewers(17).

Many studies revealed the presence of positive association between khat chewing and gender of users; males are more likely to chew khat than females $(17,18)$. Other substance use and viewing pornographic materials are important predictors of khat chewing; more number of khat chewers used other substance like alcohol and cigarette than non users; more number of khat chewers observed pornographic films than non users (16).

In spite of its serious consequences khat chewing is highly prevalent in Bahir Dar town. Even though khat chewing is the common practice study on its magnitude and predictors is scarce in the study area. Therefore, this study was conducted with the objective of assessing the extent of khat chewing and factors that might be associated with among College students in Bahir Dar town.

\section{Methods}

School based cross-sectional survey was conducted among College students in May 2012. The study was done in Bahir Dar town, Amhara National Regional State, Ethiopia. Cultivation of khat is the major source of revenue for the community living around Bahir Dar town. In Bahir Dar town there are five private and two public Colleges with a total of 4642 students.

The required sample size was calculated by single population proportion formula to address both magnitude and associated factors at confidence interval of $95 \%$, marginal error of 5\%, prevalence of $31 \%$ (from one study done in Jimma University) (19), non response rate of $15 \%$ and design effect two. The final sample size was 754 students.

Sample students were selected in a multi stage sampling technique. The required sample was allocated for each College by proportional to size allocation. Sections were selected randomly using simple random sampling technique (lottery method) from all Colleges after obtaining the list of sections from each College. Representative students from each selected section were again selected by lottery method from list of students.

Data were collected from selected students using pretested structured facilitator guided self administered questioner. The questionnaires were developed in English then translated in to Amharic (local language) and back to English. Data were collected from all students selected from one College simultaneously in one day to prevent information contamination. Data collection facilitators and supervisors were recruited and trained. They helped in seating students in the classrooms designated for completing the survey and provided explanation on the study procedures and tool. They also ensured complete privacy during completing the questionnaire.

The dependent variable was khat chewing. While the independent variables were socio-demographic characteristics of respondents, school related, parental and environmental factors. Peer pressure in this study is presence of peers who used khat and encourage students to used khat. Parental and sibling model in this study is presence of parent who used khat and sibling who used khat respectively.

Data were cleaned, coded and entered on to EPi-Info version 3.5.2 Statistical package soft ware to minimize error. Data were exported to SPSS version 16 program for analysis. The proportion of reported khat chewing was computed and then comparison was made between those reported having chewing khat and those not to identify factors that significantly differ between the groups. Logistic regression was used to control confounding effects. $\mathrm{P}$ values $\leq 0.2$ were taken a cut-off point for selecting variables for the logistic regression model. A p-value of 0.05 was considered to determine statistical significant.

The study was conducted after securing approval of Institutional Review Committee of Bahir Dar Health Science College. Written permission to conduct the study in the selected schools was obtained from the Regional Education Bureau. An informed consent was secured from each participant. The confidentiality was maintained throughout the study by not including personal identifiers from the data collection form.

\section{Result}

A total of 754 students were participated in the study. Of these 745 of them filled the questionnaires fairly completed. The response rate was $98.8 \%$. The mean age of students was 
$20.95 \pm 2.36 \mathrm{SD}$ years and $411(55.2 \%)$ of respondents were Females. The majorities of participants were Orthodox Christian followers 703(94.4\%) and from Amhara ethnic group $657(88.2 \%)$. One third $265(35.6 \%)$ of the respondents were nurse students. Nearly half $335(45 \%)$ of students were from third year and 318(42.7\%) of respondents had some amount of pocket money. (See Table 1)

Table1. Socio-demographic characteristics of respondents in Bahir Dar town, May, 2012

\begin{tabular}{|c|c|c|}
\hline variable & $\operatorname{Frequency}(n=745)$ & Percentage \\
\hline \multicolumn{3}{|l|}{ Sex } \\
\hline male & 334 & 44.8 \\
\hline female & 411 & 55.2 \\
\hline \multicolumn{3}{|l|}{ Age } \\
\hline $15-19$ years & 186 & 25.0 \\
\hline 20-24years & 505 & 67.8 \\
\hline 25-32years & 54 & 7.2 \\
\hline \multicolumn{3}{|c|}{ Level of education } \\
\hline $1^{\text {st }}$ year & 218 & 29.2 \\
\hline $2^{\text {nd }}$ year & 192 & 25.8 \\
\hline $3^{\text {rd }}$ year & 335 & 45.0 \\
\hline \multicolumn{3}{|l|}{ Religion } \\
\hline Orthodox & 657 & 88.2 \\
\hline Protestant & 66 & 8.9 \\
\hline Muslim & 22 & 3.0 \\
\hline \multicolumn{3}{|l|}{ Ethnicity } \\
\hline Amhara & 703 & 94.4 \\
\hline Oromo & 18 & 2.4 \\
\hline Agew & 18 & 2.4 \\
\hline Gurage/Tigrie & 6 & 0.8 \\
\hline \multicolumn{3}{|c|}{ Pocket money } \\
\hline Yes & 318 & 42.7 \\
\hline no & 427 & 57.3 \\
\hline \multicolumn{3}{|c|}{ Amount of pocket money(318) } \\
\hline$<100$ birr & 25 & 7.9 \\
\hline $100-200$ birr & 56 & 17.6 \\
\hline 201-300 birr & 170 & 53.2 \\
\hline$>300$ birr & 68 & 21.3 \\
\hline \multicolumn{3}{|c|}{ Place of residence } \\
\hline rural & 404 & 54.2 \\
\hline urban & 341 & 45.8 \\
\hline
\end{tabular}

The overall prevalence of khat chewing in students was $146(19.6 \%)$.Of these $92(63 \%)$ were male students. Ninety six $(12.9 \%)$ of students were currently chewing khat. Of these $62(64.6 \%)$ were male students. Among khat chewers $80(54.8 \%)$ were from third year and $100(68.5 \%)$ of students parent were from urban area. More than three fourth 116 (79.4\%) of khat chewers were chewing khat occasionally. The amount of khat consumed at a time was estimated per cost in birr and $36(24.7 \%)$ of the chewers consumed khat that costs $\geq 25$ birr per ceremony. The mean hour spent for a single khat ceremony was 4 hours. (See Table 2)

Table2. Prevalence of khat users among respondents in Bahir Dar town, May, 2012

\begin{tabular}{|c|c|c|}
\hline Variable & $\begin{array}{l}\text { Frequency } \\
(\mathrm{N}=146)\end{array}$ & $\begin{array}{l}\text { Percentage } \\
(\%)\end{array}$ \\
\hline \multicolumn{3}{|c|}{ Life time khat users } \\
\hline Male & 92 & 63.0 \\
\hline female & 54 & 37.0 \\
\hline \multicolumn{3}{|c|}{ Current khat users } \\
\hline Male & 62 & 64.6 \\
\hline female & 34 & 35.4 \\
\hline \multicolumn{3}{|c|}{ Level of education } \\
\hline $1^{\text {st }}$ year & 22 & 15.1 \\
\hline $2^{\text {nd }}$ year & 44 & 30.1 \\
\hline $3^{\text {rd }}$ year & 80 & 54.8 \\
\hline \multicolumn{3}{|l|}{ Age } \\
\hline $15-19$ years & 43 & 29.5 \\
\hline 20-24years & 88 & 60.2 \\
\hline 25-32year & 15 & 10.3 \\
\hline \multicolumn{3}{|l|}{ Religion } \\
\hline Orthodox & 124 & 84.9 \\
\hline Protestant & 12 & 8.2 \\
\hline Muslim & 10 & 6.9 \\
\hline \multicolumn{3}{|l|}{ Residence } \\
\hline Urban & 100 & 68.5 \\
\hline rural & 46 & 31.5 \\
\hline \multicolumn{3}{|c|}{ Duration of khat chewing } \\
\hline$\leq 2$ hours & 78 & 53.4 \\
\hline 3-4hours & 36 & 24.7 \\
\hline$\geq 4$ hours & 32 & 21.9 \\
\hline \multicolumn{3}{|c|}{ Money expense to buy khat } \\
\hline$<15$ birr & 76 & 52.0 \\
\hline 16-25birr & 34 & 23.3 \\
\hline$>25$ birr & 36 & 24.7 \\
\hline \multicolumn{3}{|c|}{ Frequency of khat chewing } \\
\hline Daily & 10 & 6.8 \\
\hline$>3$ times/week & 12 & 8.2 \\
\hline 1-3times/week & 8 & 5.6 \\
\hline Occasionally & 116 & 79.4 \\
\hline
\end{tabular}

Multiple logistic regression analysis revealed that khat chewing was more likely to occur among male students [Adjusted OR $=5.88,95 \% \mathrm{CI}=(3.18,10.87)]$, those had some amount of pocket money [Adjusted OR $=3.42,95 \% \mathrm{CI}$ $=(2.04,5.76)]$, those their families from urban area [Adjusted OR $=4.09,95 \% \mathrm{CI}=(2.38,7.01)$ ], those have peer pressure [Adjusted OR $=13.16,95 \% \mathrm{CI}=(6.89,25.17)$ ], parental model [Adjusted OR $=4.28,95 \% \mathrm{CI}=(1.96,9.35)$ ] and siblings model [Adjusted OR $=5.22,95 \%$ CI $=(2.05,13.28)]$. $($ Table 3$)$ 
Table3. Multiple regression analysis of khat chewing among respondents in Bahir Dar town, May, 2012

\begin{tabular}{|c|c|c|c|c|}
\hline Factor & $\begin{array}{l}\text { Khat chev } \\
\text { Yes (\%) }\end{array}$ & No (\%) & $\begin{array}{l}\text { COR } \\
(95 \% C / I)\end{array}$ & $\begin{array}{l}\text { AOR } \\
(95 \% C / I)\end{array}$ \\
\hline \multicolumn{5}{|l|}{ sex } \\
\hline Male & $92(27.5)$ & $242(72.5)$ & $2.51(1.73,3.65)$ & $5.88(3.18,10.87)$ \\
\hline female & $54(13.1)$ & $357(86.9)$ & 1.00 & 1.00 \\
\hline \multicolumn{5}{|c|}{ Pocket money } \\
\hline Yes & $100(31.5)$ & $218(68.5)$ & $3.79(2.58,5.59)$ & $3.42(2.04,5.76)$ \\
\hline No & $46(10.8)$ & $381(89.2)$ & 1.00 & 1.00 \\
\hline \multicolumn{5}{|c|}{ Residence } \\
\hline Urban & $100(29.3)$ & $241(70.7)$ & $3.22(2.19,4.74)$ & $4.09(2.38,7.01)$ \\
\hline \multicolumn{5}{|c|}{ siblings model } \\
\hline $\mathrm{Ye}$ & $16(38.1)$ & 26(61.9) & $2.71(1.41,5.20)$ & $5.22(2.05,13.28)$ \\
\hline No & $130(18.5)$ & $573(81.6)$ & 1.00 & 1.00 \\
\hline \multicolumn{5}{|c|}{ peer pressure } \\
\hline $\mathrm{Ye}$ & $58(58.0)$ & $42(42.0)$ & $8.74(5.53,13.79)$ & $13.16(6.89,25.17)$ \\
\hline No & $88(13.6)$ & $557(86.4)$ & 1.00 & 1.00 \\
\hline \multicolumn{5}{|c|}{ Parental model } \\
\hline Ye & $30(48.4)$ & $32(51.6)$ & $4.58(2.67,7.83)$ & $4.28(1.96,9.35)$ \\
\hline No & $116(17)$ & $567(83)$ & 1.00 & 1.00 \\
\hline
\end{tabular}

\section{Discussion}

In spite of its serious health, economic and social consequence of khat chewing $(3,10,20)$; in Ethiopia, the habit of khat chewing is increased from time to time $(9,21)$. Khat is widely cultivated and used by the community in the study area. In this study, $19.6 \%$ of students admitted to have chewed khat. This finding was almost in line with previous study findings in Dire Dawa High School Students, Addis Ababa University undergraduate medical students and Saudi Arabia College and secondary (high) school students of Jazan region $(7,8,22)$.

On the other hand, this finding was lower than study findings in Jimma city, southwestern Ethiopia, Eastern Ethiopia high school, Asendabo town, South Western Ethiopian youth and Axum University students $(9,18,23$, 24). This difference may be because of students' place of residence; in this study majority of students were from rural area which is an important protective factor. The second reason might be due to religion of students; in this study nearly all of respondents $(94.4 \%$ ) were orthodox Christian followers; due to religion prohibition orthodox Christian followers are not used khat than Muslim and other religions (25-27).

Gender has statistically significant and strong association with khat chewing; males were six times more likely to chewing khat than females [Adjusted $\mathrm{OR}=5.88,95 \% \mathrm{CI}=$

$(3.18,10.87)]$. This finding was supported by similar study findings in Southern, Ethiopia, Axum University, College and secondary (high) school students of Jazan region, Saudi Arabia and Somali-Australians (18, 22, 28-30). This may be due to cultural restriction; meaning females are more culturally restricted from exposure to khat chewing than males (26).
Peer pressure has statistically significant association with khat chewing; Youth who had peer used khat were thirteen times more likely to use khat than their counterparts $[\mathrm{AOR}=13.16,95 \% \mathrm{CI}=(6.89,25.17)]$. This finding is in agreement with previous study findings in eastern Ethiopia, Axum University, Ethiopia and Jazan, Saudi Arabia (18, 23, 31).This is a well established fact that youth directly persuade their friends to conform to their behavior; therefore khat chewer encourage their inexperienced peers to chew khat (32).

Family model has statistically significant and strong positive association with khat chewing practice; students with parental model (parents used khat) were more than three times prone to khat chewing than their counter parts [Adjusted OR $=3.28,95 \% \mathrm{CI}=(6.89,25.17)$ ] and those with siblings model(siblings used khat) were five times more likely to use khat than their counter parts [Adjusted OR $=6.58,95 \% \mathrm{CI}=(2.05,13.28)]$.this finding was in agreement with a previous study findins in Axum University, Ethiopia and Jazan, Saudi Arabia $(18,31)$. This is because young people tend to imitate and exercise what they observe from their siblings and parents. In addition, youth used khat to socialize with their family members(13).

Pocket money had significant association with khat chewing; Youth who had some amount of pocket money were more than three times prone to use khat than those don't have [Adjusted OR $=3.42,95 \% \mathrm{CI}=(2.04,5.76)]$. This finding was in line with study finding in Seychelles (33).The reason may be, students those have pocket money can purchase the substance that they want to use; they feel independent and used it as a means to increase social interaction(20).

Place of residence had also association with khat chewing. Students from urban parents residence were four times more likely to use khat than those their parents from rural area 
[Adjusted OR $=4.09,95 \% \mathrm{CI}=(2.38,7.01)$. This finding was opposite with the study finding among Students of Higher Education in Jazan Region, Saudi Arabia (16) ; this may be due to the more liberal life styles in urban areas compared to cultural conservatism in rural areas and may also be attributed to easiness of reporting chewing khat by urban adolescents than rural residents (26).

\section{Strength of the Study}

High response rate, large sample size, appropriate sampling procedure and analysis methods utilized were appropriate to the study and considered as the strength of the study. The study provides useful information that will inform policy makers to design a strategy to reduce the prevalence of khat chewing habit and its adverse social and health consequences.

\section{Limitations of the Study}

This study was based on cross-sectional survey; causality cannot be inferred from our findings. Relies on self response for sensitive issues can invite social desirability bias and therefore underestimate utilization of khat chewing. The study was school based; therefore precludes generalization to all youths in Ethiopia indicating a need for further study using a more representative sample of youths in the country.

\section{Conclusions}

In the study area significant numbers of College students were chewing khat. The predominant factors associated with khat chewing were being male, families from urban area, peer pressure, parental and sibling model. The findings suggest the need to have audience specific behavioral change communication to avert and prevent khat chewing practice. Colleges and health bureau should design education about consequence of khat chewing for students, their parents and the community at large to bring behavioral change.

\section{Competing Interests}

The author declare that she has no competing interest

\section{Author Contributions}

The author participated in the design, coordination of the study, data collection, statistical analysis, development and approval of manuscript.

\section{Author Information}

The author has BSC and MPH; currently working in Bahir Dar University, College of Medicine and Health Sciences, Public health department.

\section{Acknowledgement}

First of all, I would like to thank students who participated in this study and provided valuable information with their full cooperation. My thanks also go to all Colleges for their cooperation during data collection.

\section{References}

[1] John F, Louise LPL. Khat: a literature review: center for culture, ethenicity and health 2009.

[2] Ezekiel G. Khat in the Horn of Africa: Historical perspectives and current trends. Journal of Ethnopharmacology. 2010;132(3):607-114.

[3] Nasir TW. Chemistry, Pharmacology, and Toxicology of Khat (Catha Edulis Forsk): A Review. Addict \& Health. 2011;3(3-4):137-49.

[4] Magdum SS. An Overview of Khat. Addictive disorders and their treatment. 2011;10(2):72-83.

[5] Hussain.M Aa. Health and Soci-economic Hazard associated with Khat consumption $\mathrm{J}$ from community med. 2013;15(1):3-11.

[6] David MA, Neil CMC. Khat: Social harms and legislation: A literature review. home office 2011.

[7] Wakgari D, Aklilu A. Substance use and its predictors among undergraduate medical students of Addis Ababa University in Ethiopia. BMC Public Health. 2011;11(660):doi:10.1186/471-2458-11-660.

[8] Binyam N. Substance Use Among High School Students in Dire Dawa, Ethiopia. Harar Bulletin of Health Sciences. 2012(2):42-9.

[9] Tekalign D, Andualem M, Markos T. Khat chewing and mental distress:A Community based study,in Jimma city, Southwestern Ethiopia. Ethiop J Health Sci. 2011; 21(1 ):39-42.

[10] Hunter A, Baker E, Gladbaum H, Hirani K, Mashari R, McLennan M. The health and social impacts of khat use in Brent:A literature review. Brent Councile: Home Office 2012.

[11] Ishraq D, Jiří Š. Khat Habit and Its Health Effect. A Natural Amphetamine. Biomed Papers. 2004;148(1):11-5.

[12] Saba K, Ray C. Factors associated with dental and medical care attendance in UK resident Yemeni khat chewers:a cross sectional study. BMC Public Health. 2012;12(486):http://www.biomedcentral.com/1471-2458/12/ 486.

[13] Workineh G, Teferi G, Fikru T. Regular Khat (Catha edulis) chewing is associated with elevated diastolic blood pressure among adults in Butajira, Ethiopia: A comparative study. BMC Public Health. 2010;10: 390. doi:10.1186/471-2458-10-390.

[14] Dawit A, Asfaw D, Amare D, Ambaye D, Almaz A, Kelbessa $\mathrm{U}$, et al. Khat chewing habit as a possible risk behaviour for HIV infection: A case-control study. EthiopJHealth Dev. $2005 ; 3$.

[15] Ayana A, Mekonen Z. Khat (Catha edulis Forsk) chewing, 
sociodemographic description and its effect on academic performance, Jimma University students 2002. Ethiop Med J 2004;42(2):125-36.

[16] Rashad Mohammed A, MohamedSalih M, AbdelrahimMutwakel G. Khat Chewing among Students of Higher Education in Jazan Region, Saudi Arabia: Prevalence, Pattern, and Related Factors. BioMed Research International. 2013:7. dol.10.1155/2013/487232

[17] Ali WM, Zubaid M, Al-Motarreb A, Singh R, Al-Shereiqi SZ, Shehab A, et al. Association of Khat Chewing With Increased Risk of Stroke and Death in Patients Presenting With Acute Coronary Syndrome. Mayo Clin Proc. 2010;85(11):974-80.

[18] Measho G, Amsalu F, Tesfahun M. Psychoactive substances use and associated factors among Axum university students, Axum Town, North Ethiopia. BMC PublicHealth.2013;13(639):

http://www.biomedcentral.com/1471-2458/13/693.

[19] Gelaw Y, Haile-Amlak A. Khat chewing and its socio-demographic correlates among the staff of Jimma University. EthiopJHealth Dev. 2004;18(3):179-84.

[20] Patrick M, Andrew P, Kathryn H. The cost of drug use in adolescence: Young people,money and substance abuse. Drugs: education, prevention and policy. 2007;14(1):19-28.

[21] Glenice C, Hagen R. Adverse effects of khat: a review. Advances in Psychiatric Treatment. 2003;9:456-63.

[22] AgeelyHussein M. Prevalence of Khat chewing in college and secondary (high) school students of Jazan region, Saudi Arabia. Harm Reduction Journal. 2009;6(11):doi:10.1186/477-7517-6-11.

[23] Ayalu AR, Asmamaw M, Sibhatu B, Berhanu YW. Prevalence and Determinants of Khat (Catha edulis) Chewing among High School Students in Eastern Ethiopia: A Cross-Sectional Study. PLoS ONE. 2012;7(3):e33946. doi:10.1371/journal.pone.0033946.

[24] Abiye G, Abebe GM, Meseret Y. Khat use and risky sexual behavior among youth in Asendabo town, South Western Ethiopia. Ethiop J Health Sci. 2007;17(1):5.
[25] Mekonnen G. The Prevalence of Khat -Induced Psychotic Reactions among College Students: A Case in Jimma University College of Agriculture. Ethiop J Educ \& Sc. 2006;2(1).

[26] Sikiru L. Khat (Catha edulis): the herb with officio-legal, socio-cultural and economic uncertainty. South AfricanJScie. 2010;106(3-4).

[27] Kalayu M, Andualem M, Yeshigeta G. Effect of substance use on academic achievement of health officer and medical students of Jimma University, SouthWest Ethiopia. Ethiop J Health Sci. 2009;19(3):157-62.

[28] Heather D, Merali B, Nicholas L. The health impacts of khat: a qualitative study among Somali-Australians. Med J Aust 2011;195(11):666-9.

[29] Marelign TM, Gistane AA. Factors associated with KHAT use and age at first initiation among youths in southern, Ethiopia. Science Journal of Public Health. 2013; 1(3):113-8.

[30] Alsanosy, R. M., Mahfouz, M. S., \& Gaffar, A. M. (2013). Khat Chewing among Students of Higher Education in Jazan Region, Saudi Arabia: Prevalence, Pattern, and Related Factors. BioMed Research International, 2013, 7. doi: $10.1155 / 2013 / 487232$.

[31] Salih MM, Mohammed AR, Mutwakel GA. The role of family background on adolescent khat chewing behavior in Jazan Region. Annals of General Psychiatry. 2013;12(16):doi:10.1186/744-859X-12-16.

[32] Bruce S-M, Tilda F. Recent Findings on Peer Group Influences on Adolescent Substance Use. J Prim Prev. 2010;31(4):doi:10.1007/s10935-010-0220-x.

[33] Heba A, Bharathi V, Valentin R, Paccaud PBF. Association between substance use and psychosocial characteristics among adolescents of the Seychelles. BMC Pediatrics.2011;11(85): http://www.biomedcentral.com/1471-2431/11/85. 